\title{
ICONOGRAFÍA DE SANTA TERESA
}

\author{
FERNANDO MORENO CUADRO \\ Universidad de Córdoba
}

Recibido: $16 / 12 / 2020$

Aceptado: 07/01/2021

\section{RESUMEN}

Se presenta el proyecto de iconografía teresiana que he llevado a cabo en las tres últimas décadas, partiendo del deseo de conocer los temas y tipos iconográficos de una de las mujeres más importantes en la Historia de la Iglesia, la fundadora del Carmelo teresiano, a la que se han dedicado numerosas representaciones artísticas, lo que hizo que la tarea no fuera fácil por el ingente material a examinar que, finalmente, se ha dado a conocer a la comunidad científica en cuatro volúmenes que recogen los objetivos planteados, La herencia del espíritu de Elías (2016) que incardina a la reformadora en el Carmelo de la antigua observancia, Las series grabadas (2017) que permitían la trasmisión de temas y tipos, que se abordan en el tercer volumen De las visiones a la vida cotidiana (2018), para concluir con la Iconografía de los reformadores descalzos y la estampa alegórica (2919).

Palabras clave: Carmelo, grabados, emblemas, jeroglíficos, alegorías.

\section{ABSTRACT}

This is a presentation of the Teresian iconography project I have worked on for the last three decades, based on a desire to discover the themes and iconographic types of one of the key female figures in the history of the Church, Saint Teresa, the founder of the Teresian Carmel. Countless artistic representations have been made of her, which makes it a daunting task to collate them, due to the huge amount of material that has 
had to be studied. However, this has finally been made available to the scientific community in four volumes which cover the four main objectives of the study: The Legacy of the Spirit of Elijah (2016), which situates the reformer in the context of the old Carmelite doctrine, The Series of Engravings (2017), which led to the transmission of themes and types, which are, in turn, addressed in the third volume From the Visions to Everyday Life (2018), and finally the Iconography of the Discalced Reformers and the Allegorical Illustrations (2019).

Keywords: Carmel, engravings, emblems, hieroglyphs, allegories.

Debo comenzar el texto agradeciendo a los coordinadores de este dossier sobre los estudios actuales de iconografía en España e Iberoamérica la invitación para presentar en el mismo el proyecto centrado en la Iconografía de santa Teresa de Jesús, que de manera individual he llevado a cabo durante las tres últimas décadas. Este hecho lo convierte en un trabajo tan fácil de entender como difícil de explicar; de fácil comprensión porque a nadie interesado por la iconografía le extraña el interés por conocer los temas y concretar los diversos tipos iconográficos asociados a una de las mujeres más importantes en la Historia de la Iglesia, la fundadora del Carmelo teresiano, a la que se han dedicado numerosas representaciones artísticas; y difícil de explicar porque, si el objetivo general era nítido, los específicos enmarañaban el asunto haciendo que fuera complicado seguir un camino trazado previamente, el cual hacía falta diseñar a medida que avanzábamos. Y no me refiero al método de estudio, sino a la cascada de objetivos a los que respondían los múltiples interrogantes de partida, una tarea que parecía simple, pero no lo fue porque había que cubrir grandes lagunas: por ejemplo, cuáles fueron los mecanismos de configuración de la imagen teresiana, qué novedad ofrecía respecto al Carmelo de la antigua observancia, cómo se difunden los temas y el análisis de los mismos y la concreción de los tipos iconográficos. No fue posible seguir un cronograma al uso ni un camino preestablecido para lograr los objetivos por la complejidad que supuso reunir el material objeto de estudio, que, al tiempo que permitía resolver algunas cuestiones, nos planteaba nuevos interrogantes a los que se debía dar respuesta formando todo ello un complicado enredo que solo con el paso de los años fue tomando cuerpo en un esquema más o menos coherente, que respondiera y cubriera los vacíos que encontraba a cada paso, pese a ser muy conocidos algunos tipos teresianos. Cuántas veces me acordé de la perseverancia de Alciato -que se recuerda en la Idea vitae teresianae asociada a la mortificación (c.1686) y en la Ichnographia emblemática (1779) de Ignaz Verhelst en 
relación con Elías, quien, colgado de las ramas de una palma, espera recibir el alimento de un cuervo-; pero procuré no caer en el desánimo y resolví ir consiguiendo pequeños logros parciales que al final me llevaron a plantear la serie de iconografía teresiana en cuatro volúmenes de desigual extensión que responden a las cuestiones que me había planteado: La herencia del espiritu de Elías (2016), que me llevaba a incardinar a la reformadora en el Carmelo de la antigua observancia, Las series grabadas (2017), que permitían la trasmisión de temas y tipos, que abordé en el tercer volumen: De las visiones a la vida cotidiana (2018), para concluir con la Iconografía de los reformadores descalzos y la estampa alegórica (2919), que fue precisamente el origen de mi interés por la iconografía teresiana, que comenzó cuando en 1989 empezó a gestarse la celebración del IV centenario de la muerte de san Juan de la Cruz, a quien dediqué mis primeros trabajos de tema carmelitano, centrados fundamentalmente en las fundaciones del descalzo en Córdoba: San Juan de la Cruz y Córdoba. El Convento de Santa Ana (1989), y los catálogos de exposiciones que se organizaron con motivo de la efeméride, como la del fondo de Raros de la Biblioteca de la Curia Provincial de Andalucía O.C.D. (1991), la de San Juan de la Cruz en el grabado organizada por la Caja Bilbao Vizcaya (1991) y la organizada por la Junta de Andalucía con el título de Iconografía y arte carmelitanos (1991) y la muestra San Juan de la Cruz y el grabado carmelitano del Teresianum de Roma (1991), organizada por el Ministerio de Cultura, la Universidad Internacional Menéndez Pelayo y el Consejo Superior de Investigaciones Científicas junto a las embajadas de España ante la Santa Sede y ante el Quirinal, de la que dependía como becario del Ministerio de Asuntos Exteriores; ello me permitió comenzar el estudio de la estampa carmelitana, pues en Roma pude trabajar, además de en el Instituto Histórico del Teresianum, Centro Internacional de Estudios de O.C.D. y en el Colegio Internacional San Alberto (O.C.), en los Archivos de las Curias Generalicias de los Carmelitas -Calzados y Descalzos-, en la Biblioteca Vaticana, en la Galería Nacional de la Estampa y en el Archivo Fotográfico del Ministerio de Bienes Culturales, los más importantes centros de repertorios grabados centrados o relacionados con el tema abordado. Todo ello me facilitó la realización de un importante repertorio de grabados teresianos, que completé recogiendo las fuentes grabadas de los grandes archivos y bibliotecas nacionales de los países que fueron importantes centros productores de estampas, en los que la Orden tuvo arraigo, además de las de museos monográficos de estampas -Plantin-Moretus de Amberes- o con secciones importantes dedicadas a las mismas -Calvet de Avignon y Carnavalet de París, entre otros-, y de los archivos y bibliotecas de las curias provinciales que centralizan muchas fuentes bibliográficas y estampas, así como los de todos aquellos conventos carmelitas a los que pudiera tener acceso, lo que me permitiría no solo conocer 
el material grabado objeto primero de estudio, sino también un amplio repertorio de manifestaciones artísticas relacionadas con el mismo.

La amplitud del proyecto: España, Portugal, Francia, Países Bajos -especialmente Bélgica-, Centroeuropa-Alemania, Polonia, Praga y Austria-, Italia y América -Chile, Colombia y particularmente México, a donde llegaron los carmelitas en septiembre de 1585 y donde a partir del año siguiente comenzaron a fundar conventos en la meseta del Anáhuac--, ha sido el mayor obstáculo a la hora de concluir el estudio centrado en la difusión de la iconografía a partir de la estampa teresiana, destinada a cubrir unas necesidades transmitiendo información y los nuevos tipos iconográficos que la Descalcez carmelitana deseaba propagar entre sus religiosos y a toda la sociedad, en la que penetraba a través del comercio y consumo, convirtiéndose en un excepcional medio de comunicación y, consecuentemente, en el más importante vehículo de difusión de modelos formales y tipos iconográficos. En ello insiste nuestro trabajo, partiendo del intenso uso que la Iglesia hizo de la imagen para proyectar su doctrina desde el primer arte cristiano, siguiendo un planteamiento que no era nuevo, pues los filósofos griegos ya destacaron el sentido de la vista como el del conocimiento, lo que fue retomado por los grandes teólogos cristianos, regenerándose con Trento esa concienciación por parte de la Iglesia de la importancia de las artes visuales en la predicación del Evangelio. La Contrarreforma fue determinante en la propagación de todo tipo de imágenes con el objetivo de demostrar visualmente las verdades de la Iglesia Católica, lo que, unido al desarrollo del grabado calcográfico, hizo que se produjera y difundiera un gran número de estampas, temática que, centrada en la reformadora del Carmelo, determina el estudio que aquí presentamos.

El conocimiento y expansión de motivos y tipos iconográficos a través de la estampa son bien conocidos: recordemos a Francisco Pacheco, quien defiende su uso y cita frecuentemente a Jerónimo Nadal; pero la estampa no solo es un vehículo difusor de tipos iconográficos, sino también de estética, rompiendo el aislamiento artístico, siendo especialmente significativa en este sentido su proyección por Iberoamérica, pues permitía entrar en contacto con las grandes obras de arte que no era posible conocer directamente. En la difusión de estética e iconografía por la estampa tuvo un importante papel la monarquía hispana: recordemos que Felipe II mandó se aplicaran las órdenes de Trento en todo su imperio como si fueran leyes y potenció la difusión de impresos que incluían imágenes, que en el siglo XVI proceden casi en su totalidad de Amberes, siendo el impresor más importante Cristóbal Plantin (1520-1589), que tuvo el monopolio de la estampa y una serie de privilegios, de Felipe II y de los pontífices, que le permitieron vender libros litúrgicos no solo en el imperio 
español sino también en Francia, Alemania e Italia. Con dieciséis prensas en marcha, es considerado el primero de los grandes impresores industriales, continuando su labor sus sucesores, los Plantin-Moretus. De esta manera, Flandes se convirtió en el origen de un gran número de grabados que, como ha subrayado Delen, viajaban de Amberes por Europa, a París, Roma, Lisboa y Sevilla, desde donde se trasladaban a América.

En relación a las estampas importadas destinadas a difundir tipos iconográficos, conviene aclarar el proceso creativo de las mismas, que en el caso de la descalcez carmelitana en la que nos centramos se pergeñaba por españoles o en España, donde se encontraba el centro de la reforma teresiana que generaba los temas y tipos que se querían propagar y se materializaban por diferentes artistas, fundamentalmente grabadores flamencos, cuyas estampas se distribuían por los conventos y sus radios de influencia para expandir los nuevos tipos que, en muchas ocasiones, servían a otros artistas como modelo a imitar o como fuente de inspiración. Esas estampas, generalmente formando series que se convertían en la base para la iconografía posterior del personaje al que se dedicaban con motivo de su beatificación o canonización, estaban pensadas por los historiadores y teólogos de la Orden, quienes conocían bien los hitos culminantes que podían ofrecer una visión lo más completa posible de sus vidas y de su servicio a la Iglesia, y se realizaban para generalizar una visión oficial que servía de referente no solo a los miembros de la Orden sino también al resto de la cristiandad, a la que comunicaban la fama del nuevo beato o santo y la fama de la Orden a la que pertenecía. Estas ideas se concretaban por artistas pintores y grabadores-, que las materializaban en imágenes y las grababan para su mayor difusión, siendo Amberes uno de los centros productores más importantes de estampas junto a París, Lyon, Venecia y Roma, donde solía editarse la estampa oficial con un cuadro central -en el que se destaca la escena considerada como la más característica y emblemática- rodeado de otros episodios representativos de su vida, que se ampliaban en las estampas que ilustraban sus biografías o en las series editadas con breves explicaciones al pie, incidiendo en la difusión de conceptos a través de la imagen. Ello se subraya, por ejemplo, en la presentación de la Vita B. Virginis Teresiae que fue publicada en Amberes, en casa de Adrianum Collardum y Cornelius Galleum, en 1613, en la que se destaca que se realizó con la intención de llegar «con esta ayuda a los ojos» a un mayor número de fieles, despertando su admiración y suscitando la imitación de la santa de Ávila, pues su vida «tantas veces escrita y leída, penetra poco en los espíritus», idea con la que termina de forma inusual la dedicatoria latina a su benefactor, don Rodrigo Lasso Niño, conde de Añover, administrador y camarero mayor del Serenísimo Archiduque Alberto. 
La importancia de la estampa desde el punto de vista estético e iconográfico está en la base del estudio de iconografia teresiana a partir de la imagen grabada que presentamos, considerando la estampa de una manera total y globalizadora, concebida como un instrumento de conocimiento, contenedor de ideas y saberes, y como un medio de comunicación y fijación de conceptos en la memoria. Como un arte que se utiliza tanto para despertar la devoción y persuadir visualmente, a manera de sermón moralizador, como para simbolizar emblemáticamente una idea y como medio que, sobrepasando los valores humanísticos y artísticos, se ponía al servicio de la Orden para difundir los principios que defendía. Un estudio en el que ponemos de manifiesto cómo la iconografía no es localista sino universal y en el que demostramos nuestro presupuesto de inicio: la estampa como importante vehículo transmisor de contenidos iconográficos y estéticos. Un estudio en el que presentamos un planteamiento iconográfico integral, proceso de creación, difusión conceptual y repercusión artística, que es constante en la estampa teresiana, lo que nos ha permitido establecer el papel que adquiere en las obras de los grandes maestros flamencos -Rubens...-, italianos -Bernini, Tiépolo...-, españoles -Rizi, Ribera...- y mexicanos -Villalpando...-, entre otros, aunque lo que planteamos va más allá de la identificación de fuentes iconográficas de destacadas obras artísticas porque, aun siendo importante, lo que nos interesaba poner de manifiesto era el proceso seguido en la génesis iconográfica de las obras dedicadas a santa Teresa de Jesús durante el Barroco y su significado en relación a la expansión de la Orden y la ingente labor de evangelización realizada en la Europa protestante y América, en las que tuvo una importante presencia por su marcado espíritu misional. Todo ello favoreció la realización de obras destinadas a las nuevas fundaciones con las que comunicar su historia y los principios doctrinales que defendía: espíritu eliano, cristología mariológica... y santos, entre los que destaca de manera fundamental la reformadora descalza, cuya iconografía abordamos ampliamente, desde las series de estampas que la consagran y sirven de fuente de inspiración a numerosos artistas de Europa y América, hasta la conceptualización de la imagen.

El trabajo se estructura en cuatro libros que abarcan las temáticas fundamentales de la iconografía teresiana y se corresponden de manera general con los principales objetivos planteados que se desgajaron en otros objetivos específicos, a los que hemos intentado dar respuesta en cada uno de los diferentes capítulos destinados a considerar los matices más destacados. El primero está dedicado a La herencia del espíritu de Elías (Fig. 1), que responde fundamentalmente a lo que supone la descalcez respecto al Carmelo de la antigua observancia, y en el mismo se presentan, en primer lugar, las obras destinadas a poner 
de manifiesto uno de los principios fundamentales del Carmelo teresiano: la reacción contra la relajación que había sufrido la Orden y la vuelta a la primitiva austeridad, conectando con la tradicional iconografía ligada a Elías, su mítico fundador - tal como aparece en la escultura de la basílica de San Pedro del Vaticano-, al que se considera precursor del movimiento monástico del siglo IV, que lo tuvo como modelo de perfección -pobreza, continencia, soledad en el desierto, vida de oración...-, aunque en realidad no fue el impulsor espiritual ni jurídico del monacato.

Uno de los medios más claros y didácticos para expresar estas ideas fueron las manifestaciones artísticas surgidas en el seno de la descalcez carmelitana con la finalidad de ser difundidas en su ámbito de influencia, centradas en imágenes que sintetizaban los conceptos básicos que defendía e impulsaba, sirviendo de apoyo a quienes tenían que explicarlos, y con el tiempo se convertían, a la manera de los emblemas, en recuerdo para la memoria.

La puesta en marcha de este proceso surgía en la dirección de la Orden, que contaba, como hemos indicado, con un círculo de intelectuales, historiadores y teólogos que ideaban y establecían los modelos que se mandaban grabar a los grandes centros productores de estampas con la finalidad de facilitar su difusión en su cada vez mayor ámbito de influencia. La presencia de un solo emisor y de varios receptores acarreó que las distintas comunidades las recibieran de manera diferente, aunque en muchos casos se materializaron en obras plásticas casi idénticas, con más o menos desarrollo. Unas veces han llegado hasta nosotros variados ejemplares, tanto españoles -Córdoba, Pastrana, $\mathrm{Nu}-$ les- como hispanoamericanos -México y Guadalajara-, que presentan a los reformadores descalzos bajo el manto de Elías que recibe Eliseo, relacionándolos con los primeros seguidores del personaje veterotestamentario, mientras que en otras ocasiones los ejemplares conocidos ponen de manifiesto, además de la amplitud geográfica -Córdoba, Beaume, Roma...-, la especial significación de una temática ligada a la Contrarreforma, como la defensa de María por los carmelitas, ilustrando uno de los principios básicos de la Orden -actio y contemplatio- que los vuelve a Elías, un hombre de oración -retiro al torrente de Querit-y de acción -lucha contra los profetas de Baal-. Constituye esta una defensa eliana de la verdad que fue retomada por la labor misional del Carmelo teresiano a través de sus nuevas fundaciones en las zonas de Europa por las que se había extendido el protestantismo, y en América, asimilándolas a vergeles que se conectan con el paraíso carmelitano/Monte Carmelo, el jardín de Yahvé donde crece la viña carmelitana/teresiana, uno de los temas más extendidos, como ponen de manifiesto los ejemplares de San Ángel de México, La Soledad de Puebla, San José de Santiago de Chile y Sanlúcar la Mayor, entre otros. 
El segundo capítulo se centra en la protección y mediación de María, a quien está consagrada la Orden, siendo este carácter mariano uno de los más importantes aspectos del cristocentrismo de los carmelitas, quienes sirvieron a Cristo sirviendo a María, a la que adoptan como madre y patrona de la Orden, la cual es protegida por la Virgen del manto y recibe singulares privilegios, como el recogido en la Bula Sabatina en relación con el escapulario. Son temas carmelitanos clásicos que asumen los descalzos, los cuales reciben el escapulario siguiendo la tipología más habitual de las representaciones de san Simón Stock, al que se equipara la santa abulense en algunas obras, en las que aparece recibiendo la singular insignia de manos de Jesús Niño al tiempo que el carmelita británico la recibe de María, destacando entre las variedades la excepcional pintura de Tiépolo: La Madonna del Carmelo (c. 1730), de la Pinacoteca Brera de Milán.

En la misma línea habría que situar otro de los aspectos que abordamos en relación con María -Decoro del Carmelo-, en torno a la cual se desarrolla la Orden que la exalta en diversas apoteosis en las que participa santa Teresa, cuya iconografía adapta la tradicional de la Virgen del manto convirtiéndola en la particular temática del Manto teresiano, bajo el que se refugian los descalzos, desarrollada a partir de la estampa que grabó Adriaen Collaert para la Vita ... de Amberes de 1613.

Asimismo, la iconografía de santa Teresa se asocia a otro de los más importantes temas carmelitanos, el de la Inmaculada, que entronca con la Visión de la nubecilla por medio de la cual se reveló a Elías que nacería una mujer inmune de pecado original que sería la madre del Mesías, motivo por el que los carmelitas sobresalieron entre las órdenes religiosas que asumieron la defensa de la Inmaculada Concepción de María, llegando a crear, de este modo, un tipo muy singular, el de la Inmaculada carmelitana, que estuvo muy difundido en Europa y cuenta con importantes ejemplos en América al servicio de la monarquía de Carlos III, como he matizado recientemente en mi artículo dedicado a la Inmaculada carmelitana en Goya ( ${ }^{\circ}$ 370, 2020: pp. 30-47), presentándose frecuentemente la Virgen del Carmen con los símbolos inmaculistas -alas de la Mujer apocalíptica, media luna, coronada de estrellas...-, respondiendo en definitiva al modelo de mujer perfecta que se transforma en mediadora y salvadora, lo que se recoge de manera excepcional en una particular visión trinitaria de María, perteneciente a una colección particular de México - donde fue frecuente la representación de la Trinidad antropomorfa-, convirtiéndose en uno de los más originales ejemplos de representaciones marianas que se vinculan a santa Teresa. 
A la expansión del Carmelo dedicamos el capítulo tercero, en el que tratamos cómo la descalcez presenta el Monte Carmelo, primitivo lugar eliano en el que se reunieron los seguidores del profeta que dieron origen a la Orden, como el centro del mundo y de las nuevas fundaciones teresianas. Es una temática en la que, junto a la materialización de hechos históricos concretos, alcanza un gran protagonismo el simbolismo y la alegoría que sintetiza de manera muy original el fomento de la vida regular con la representación de santa Teresa junto a modelos de edificaciones -Pastrana, Duruelo...- que añaden a la expansión llevada a cabo por la santa abulense de monasterios femeninos los conventos de los descalzos.

Dentro de la expansión dedicamos un apartado a la nave misional, que simboliza una de las vocaciones del Carmelo teresiano, guiada por la fundadora de la descalcez, que tuvo una importante labor en América y especialmente en México, cuya presencia se sintetiza con dos excepcionales ejemplos que simbolizan La provincia de San Alberto de México como «Casa de la Sabiduría» y La nueva Jerusalén carmelitana de Puebla.

En el segundo volumen (Fig. 2) se aborda un tema básico: cómo se difunden los temas y tipos iconográficos teresianos y qué medio se utiliza por la Orden para ello, centrándose en Las series grabadas dedicadas a la reformadora descalza, que destacan por su diversidad y amplio número, jalonándose desde principios del siglo XVII a finales del barroco, acomodándose a las necesidades y expectativas del público al que estaban dirigidas.

Se analiza ampliamente la serie de Collaert-Galle para complementar la positio (1613) de la beatificación (1614) que se volvió a reeditar en 1630, después de la canonización (1622), para la que no se realizó ninguna en especial, volcándose toda la atención en la estampa oficial grabada con motivo de la celebración, centrada en la transverberación que estuvo bordeada por los principales milagros presentados a la Congregación para las Causas de los Santos.

En el último tercio del siglo XVII, tras el incremento de temas que surgieron a mediados de la centuria, y coincidiendo con la amplia expansión que había tenido el Carmelo teresiano y la edición de la espléndida serie grabada dedicada a santa María Magdalena de Pazzi con motivo de su canonización (1669), se realizaron, sin apenas variantes, las series de Lyon y Roma (1670) que fueron adaptadas a la estética del setecientos por Arnold van Westerhout en 1715.

Con ellas parecían haber concluido los ciclos de estampas dedicados a santa Teresa, pero el siglo XVIII presenta una sorprendente variedad, con singulares series de diferente calidad y significado, desde la que ilustra el Mistico Ritratto (Módena, 1697), con imágenes que ayudan a la meditación sobre su 
vida, a la realizada por los Klauber, dentro de la amplia actividad que desarrollaron los grabadores alemanes en el segundo tercio de la centuria, que no presenta una renovación temática, pero si un destacado cambio en el planteamiento, vinculando los más destacados temas del ciclo vital de santa Teresa con los signos del Zodiaco.

Mención aparte merecen la grabada en Praga por Anton Birkhart con diseños de Johann Hiebel y la realizada por el primer director de la Sección de Grabado de la Real Academia de Bellas Artes de San Fernando, Juan Bernabé Palomino, para ilustrar las Cartas y Obras de la Gloriosa madre Santa Teresa de Jesús..., editadas en Madrid por Joseph Orga en 1752, que se adaptan a sus respectivas zonas de influencia, en las que contrastan los clásicos temas de Hiebel con los de la serie madrileña que presenta novedosas síntesis de destacados conceptos carmelitanos junto a tradicionales temas teresianos renovados.

El tercer tomo (Fig. 3) recoge los más importantes temas de iconografía teresiana: De las visiones a la vida cotidiana, partiendo de un análisis previo sobre el valor de la imagen visionada y artística para la carmelita, que tenía una gran «dificultad para con el entendimiento representar cosas, que si no era lo que veía no me aprovechaba nada de mi imaginación... por eso era tan amiga de imágenes» artísticas (Vida 9, 6), diferentes de la IMAGINARIA VISIO o visión de imágenes que permiten el acercamiento a Dios y recogió Antonine Wierix en su serie sobre Los estados de la vida mística.

Tras el análisis de su actitud ante la imagen visual, dedicamos especial atención al análisis del papel que tuvieron las visiones -imaginarias e intelectuales- para la santa abulense, que las consideró «libro vivo» a través del cual Dios transmitía sus enseñanzas al alma, por lo que se convirtieron en fuente iconográfica de gran parte de las obras que se le dedican. Comenzamos por las de la humanidad de Cristo, que abordamos en el segundo capítulo a partir de la primera visión imaginaria que tuvo, la del Resucitado -Alonso Cano, Museo del Prado-, aunque también contempló al Señor en diferentes escenas de la Pasión, ya que «sólo podía pensar en Cristo como hombre», convirtiendo la naturaleza humana de Jesucristo en camino de santificación y los sufrimientos que soportó para redimir la humanidad en su programa de vida, como otros fundadores y reformadores, destacando en el ámbito carmelitano la similitud del término «padecer» como camino de existencia para sus más destacados representantes del siglo XVI, coincidiendo en lo esencial el «aut pati, aut mori» teresiano con el «pati, non mori» de santa María Magdalena de Pazzi y el sanjuanista de «pati et contemni pro te». Por ello, van a ser numerosas las representaciones de las escenas pasionistas -Cristo a la columna, Cristo llagado...-, 
asimilando la visión del Nazareno ignaciana -Storta- y sanjuaniana -Segovia-, como también lo hizo san Juan de Ávila -Puerta de Elvira de Granada-. Son asimismo frecuentes las visiones de Cristo con signos de la Pasión, con la corona de espinas, con uno de los clavos que entrega a santa Teresa simbolizando su matrimonio espiritual, u ofreciéndole una cruz; pero siempre, aunque estuviese en tribulación, se le muestra «la carne glorificada» (Vida 29, 4), punto de mira de la existencia vital teresiana.

No obstante la importancia que adquiere la representación de la humanidad de Cristo en la iconografía de la santa abulense, la temática fundamental de la misma es la transverberación, a la que se dedica un amplio capítulo. Se recogió en la serie de Collaert-Galle para la positio de la beatificación, pero se desarrolló especialmente a partir de la canonización (1622), pues fue el motivo central teresiano de la estampa oficial de Matteo Greuter editada con motivo de las celebraciones en San Pedro del Vaticano, aunque el modelo que en ella se representó no fue el más difundido, si bien está en la base de algunas manifestaciones artísticas, en las que establecemos varios grupos a los que se pueden adscribir la mayoría de los ejemplos conocidos.

Dedicamos un epígrafe al corazón transverberado que se venera en el monasterio carmelita de Alba de Tormes, en un relicario diseñado por Herrera Barnuevo. Son numerosas las estampas que lo presentan ardiente de amor, como receptáculo de María y de Cristo, que se considera la medida del mismo, siguiendo una temática que tuvo especial repercusión en determinados miembros de la Orden -Venerable Paula María de Jesús-, y lo hemos vinculado con las representaciones de destacadas carmelitas para las que el corazón constituye parte esencial de su iconografía: tal es el caso de Ana de San Bartolomé, Ana de Jesús y santa María Magdalena de Pazzi.

A pesar de los paralelismos citados de mutua posesión y ofrecimiento del corazón a Dios/Santísimo Sacramento, la mayoría de las manifestaciones artísticas ligadas al corazón teresiano se centran en la transverberación, que se vincula con frecuencia a otras temáticas, entre las que destaca especialmente la de escritora. Es este uno de los grandes temas de la iconografía de santa Teresa, que enlaza su tarea intelectual con la transmisión de su doctrina a los descalzos, a quienes enseña el camino de la meditación/oración como paso fundamental para la unión con Dios, lo que incide en las dos ideas básicas del Carmelo teresiano: la contemplatio y la actio, esta última centrada en las tareas de la vida cotidiana, entre las que, para santa Teresa, se incluía la de escribir.

Junto al planteamiento general del corazón teresiano, presentamos las tipologías más destacadas de la transverberación, desde los clásicos modelos 
flamencos del seiscientos -Serafín/querubín de Collaert, las figuraciones de Mallery y Bouttats ante un altar y la influencia de Anton Wierix el Joven-hasta el pleno arrobamiento -Gianlorenzo Bernini, la influencia de los Officia Propria y algunos singulares ejemplos centroeuropeos-, y analizamos el gran desarrollo que alcanzó en el último tercio del siglo XVII el tema de la transverberación vinculado al misterio trinitario, especialmente desarrollado en la serie de la transverberación con las dos Trinidades que deriva de una singular estampa de Wierix.

Capítulo independiente dedicamos a la vera effigies, uno de los temas más difundidos de iconografía teresiana a partir del retrato que le hizo fray Juan de la Miseria en Sevilla (1576) para contentar a la comunidad del nuevo monasterio de San José del Carmen -Las Teresas- de la separación de la fundadora, a la que deseaban tener presente en sus vidas, motivo por el que surge la vera effigies, que se copia por quienes, no teniendo la posibilidad de contar con un retrato original, anhelaban convertirla en punto de mira de su quehacer.

Francisco Pacheco en el Arte de la Pintura y Antonio Palomino en el Museo Pictórico se hacen eco de la enorme expansión del verdadero retrato de la reformadora descalza, al que dedicamos en nuestro trabajo un extenso análisis, ofreciendo una visión en la que establecemos diferentes grupos con las distintas tipologías iconográficas vinculadas a la vera effigies, que suele combinarse con la transverberación -S. à Bolswert y Cornelio Galle- y la temática de escritora, por separado o conjuntamente, como la presenta José de Ribera en el singular lienzo del Museo de Bellas Artes de Sevilla.

La fusión de temas señalada no solo responde a una economía de medios, sino especialmente a vincular el verdadero retrato de la santa abulense con los tipos iconográficos más significativos de la misma, siendo en este sentido fundamental para sus seguidores la del magisterio teresiano, ya que unía enseñanzas y maestra en una sola representación. Por ello, pensamos que tuvo tanto éxito la temática que comenzó tímidamente en la Vita ... de Roma de 1599, en la que se figuró a la reformadora descalza en una mesa con los símbolos de escritora y un libro abierto, que también aparece en La Beata Teresa de Giovanni Vicenzo Imperiale (Génova, 1615), y se funden con el ejercicio de escribir a partir del retrato teresiano de Zaragoza, que ilustra la edición de Los Libros de la B. Madre Teresa de Iesvs..., publicada por Pedro Cabarte en 1615, que tuvo una enorme repercusión, seguida por grabadores y pintores, directa o indirectamente, a través de estampas derivadas, como la de J. Sadeler, que abre la estancia al exterior a través de una ventana, frente a la grabada por E. Müller 
en Colonia, de la que se conoce una versión pintada en el carmelo de Würzburgo.

A santa Teresa escritora está dedicado el siguiente capítulo, en el que se analizan las variantes surgidas en los frontispicios de libros, centrándonos fundamentalmente en el momento de la inspiración divina -con la presencia de ángeles y acompañada de las virtudes teologales- y en el magisterio teresiano y sus fuentes -Sagradas Escrituras, santo Tomás y el libro vivo de las visiones imaginarias e intelectuales...-, destacando los más importantes ejemplos, desde los que siguen los modelos alcantarinos hasta los realizados por Pedro Pablo Rubens, Juan Correa, Gregorio Fernández, Pedro de Mena, Alonso Cano, José de Mora..., junto a los de José Ribera que ya hemos comentado.

Analizamos asimismo el singular grupo de obras que reflejan cómo las enseñanzas de santa Teresa trascienden el interior monástico, en las que se figura a la reformadora dirigiéndose desde una cátedra a un nutrido grupo de clérigos, como la representó F. Ioseph en una estampa que gozo de cierta difusión con versiones pintadas o talladas, entre las que destacan los ejemplares de Toro (Zamora), Pastrana (Guadalajara), Nules (Castellón de la Plana) y Guadalajara (México).

Junto a la labor intelectual, uno de los ámbitos más interesantes de la iconografía teresiana es el de las tareas domésticas, que abordamos en el último capítulo. Son temas que no aparecen en los repertorios oficiales, sino en determinados monasterios con la finalidad de simbolizar emblemáticamente el valor de la cotidianidad para la descalcez carmelitana como símbolo de la fortaleza y la humildad que permite progresar en la oración; en ello incide la estampa de Presost - «Sans l'Humilité on s'avancera jamais dans l'Oration»-, que complementa la imagen de santa Teresa en oración delante de un crucifijo con la de la religiosa en la cocina, como la representó Francisco Rizi en el simbólico lienzo del monasterio de San José de Ávila.

Destacamos también el interesante matiz que muestran algunas obras novohispanas, como el lienzo conservado en el convento mexicano de Guadalajara, que figura a la santa abulense hilando como la «mujer fuerte» de los Proverbios, cumplidora de sus deberes, aunando el trabajo manual con el intelectual -escritorio, libros, birrete...- para poner de manifiesto la indisolubilidad de ambos, como había aparecido en las estampas de Francisco Villamena de Santa Teresa escritora y de Hieronymus Wierix de su vera effigies, aunque en el lienzo de México se presenta -a diferencia de los modelos europeos- un predominio del trabajo manual, debido probablemente a que la intelectualidad en 
el ámbito social en el que surge era minoritaria frente a otros tipos de actividad, aunque ambas se presentan asociadas en la reformadora descalza.

En el cuarto tomo, bajo el título Iconografía de los reformadores descalzos y la estampa conceptual (Fig. 4), se presentan los últimos aspectos de iconografia teresiana que consideramos fundamentales, comenzando por la configuración de la imagen teresiana a partir de las celebraciones festivas, destacando el papel del jeroglífico en las celebraciones públicas, en las que se incluyen en el apartado de jeroglíficos algunos «passos» de la Vita de Amberes de 1613, la serie de Collaert, compuesta por estampas con pictura, lema y epigrama que, en muchos casos, suele incluir el lema, describiendo Cipriano de Aguayo el retrato teresiano de Cornelio Galle utilizando la terminología emblemática: «a Santa Teresa píntala cercado el rostro de rayos y resplandores nueva insignia de su beatificación, y al Espíritu Santo en figura de paloma aleando delante de su rostro, señal de que de propósito la enseñó y ilustró. A su lado pintan la palma triunfadora de nuestro Salvador, que es la Cruz, a quien la Santa está arrimada y por el tronco della ondeada esta inscripción Aut pati, aut mori, palabras que con afecto grande solía decir la Santa a Dios en el fervor de la oración, Señor o salir de esta vida y morir, o padecer continuamente por vos: finalmente ponerle por blasón y mote como que le sale de la boca estas palabras del Salmo 88, Misericordias Domini in aeternum cantabo. Para siempre cantaré las misericordias del Señor» (Sermones predicados en la Beatificación de la B. M. Teresa de Iesvs Virgen, Fvndadora de la Reforma de los Descalzos de Nuestra Señora del Carmen, Madrid, Viuda de Alonso Martín, 1615, p. 99).

Una temática que se repite de manera habitual en las series particulares de los dos reformadores del Carmelo es la relación de santa Teresa y Juan de la Cruz, a quien dediqué mis primeros estudios de grabados carmelitanos; por ello, en el segundo capítulo se ofrece una visión de la iconografía teresiano-sanjuaniana, a la que se alude inevitablemente en todos los volúmenes de Iconografía de santa Teresa que presentamos, partiendo de las obras dedicadas a la santa abulense, que completamos con las que recogen su presencia en las representaciones sanjuanistas, como el repertorio de Gaspar Bouttats para ilustrar la obra de Gaspar de la Anunciación, Representación de la vida del Bienaventurado P. F. Ivan de la Cruz..., publicada en Brujas en 1678, tras su beatificación, presentando los tipos más habituales de la iconografía conjunta de los reformadores descalzos -Encuentro en Duruelo, instrucción de san Juan de la Cruz en la reforma teresiana, sucesión del Carmelo eliano, levitación en el locutorio del convento de la Encarnación de Ávila al hablar sobre el misterio de la Santísima Trinidad, enseñanza espiritual...-, entre las que destacamos especialmente la asimilación iconográfica que presenta Gregorio Fosman en la estampa que 
ilustra la obra de fray Antonio de Jesús María sobre D. Baltasar Moscoso... (Madrid, 1680), que figura a los dos santos transverberados en la cumbre del Monte Carmelo, uniendo sus corazones al de Cristo con los conocidos lemas «aut mori, aut pati» y «pati et contemni...» que sintetizan el programa de vida de los reformadores descalzos.

La investigación concluye con una visión de las estampas pedagógicas y alegóricas. Las primeras estuvieron destinadas a mostrar aspectos concretos de forma accesible a los fieles y entre ellas destaca, además de las vinculadas al programa espiritual sanjuanista, del que se hicieron numerosas versiones y del que se hace partícipe a santa Teresa, el Ars moriendi teresiano elaborado por Francisco de la Cruz con imágenes parlantes destinadas a la asistencia espiritual «para vivir y morir bien», del que se imprimieron varias ediciones en Italia y España. Más interés tiene la estampa alegórica, tanto por lo que respecta a las representaciones teresianas como a la descalcez carmelitana, que se muestra como una de las órdenes religiosas más participativas de la cultura emblemática que tan amplio desarrollo tuvo en la Edad Moderna,

Paralelamente se desarrolló una línea marcada por los libros de emblemas, que comenzaron en el ámbito teresiano a partir del realizado por Giovanni Vincenzo Imperiale, La Beata Teresa, publicado en Génova en 1615, al poco tiempo de su beatificación, en el que se presentan las cualidades de la carmelita con seis emblemas, en los que se utiliza el clásico lenguaje gráfico-literario que también se emplea para sintetizar complejas explicaciones, como las de Juan de Rojas a Las Moradas teresianas, o ilustrar sermones, como los de Fray Diego de la Expectación, A Estrela D'Alva a sublissima, e sapientissima mestra da Santa Igreja, a angelica, e seráfica doutora mystica Santa Theresa de Jesus, may, e fila do Carmelo: Matriarca, Fundadora de su sagrada Reforma, publicados en Lisboa y Coimbra en 1710 y 1716 respectivamente.

El emblema también se utilizó con frecuencia en el ámbito de la descalcez carmelitana para completar frontispicios de libros o estampas -como las grabadas por Juan Bernabé Palomino en 1752-, pero donde se hace más evidente su singular uso por el Carmelo teresiano es en el excepcional tratado sobre la vida mística publicado con el título de Idea Vitae Teresianae, en el que la alegoría se presenta al servicio de la mística y espiritualidad carmelitana, que analizamos con detenimiento, vinculando parte de sus alegorías con la iconografía teresiana que centra nuestro trabajo. 


\section{BIBLIOGRAFÍA}

COLLAERT, A. y GALLE, C., Vita B. Virginis Teresiae a Iesv ordinis carmelitarum excalceatorum piae restauratrices, Antwerp, 1613.

DE JESÚS MARÍA, A., Baltasar de Moscoso i Sandoual, Presbytero Cardenal de la S.I.R. del titulo de Santa Cruz en Ierusalem, Madrid, Bernardo de Villa-Diego, 1680.

DE LA ANUNCIACIÓN, G. y BOUTTATS, G., Representación de la vida del Bienaventurado P. F. Ivan de la Cruz primer Carmelita descalço, Brujas, Pedro van Pée, 1678.

DE LA EXPECTACIÓN, A., A Estrela D'Alva, a sublissima, e sapientissima mestra da Santa Igreja, a angelica, e serafica doutora mystica Sta. Theresa de Jesus, Lisboa, 1710 (tomo I) y Coimbra, 1716 (tomo II).

DE ROJAS, J., Representaciones de la verdad vestida, misticas, morales y alegóricas, sobre las siete moradas de Santa Teresa de Jesús, Madrid, Antonio Gonçalez de los Reyes, 1677.

DE SANTA. BÁRBARA, A. $M^{a}$, Mistico ritratto della Serafica Vergine Santa Teresa di Giesù, Módena, 1697.

ICHNOGRAPHIA emblematica triplicis al Deum Tri-unum mysticae viae, purgativae, illuminativae, unitivae, Augsburg, Ignaz Verhelst, 1779.

IDEA VITAE TERESIANAE iconobus symbolicis expressa, in quinque partes divisam, Antverpiae, apud Jacobum Mesens, (c.1686).

IMPERIALE, G. V., La Beata Teresa, Genova, Giuseppe Pavoni, 1615.

MORENO CUADRO, F. y PALENCIA CEREZO, J. M ${ }^{\mathrm{a}}$, San Juan de la Cruz y Córdoba. El Convento de Santa Ana Córdoba, Monte de Piedad y Caja de Ahorros de Cordoba, 1989.

MORENO CUADRO, F., Iconografía de Santa Teresa (I): La herencia del espiritu de Elías, Burgos, Monte Carmelo, 2016.

MORENO CUADRO, F., Iconografía de Santa Teresa (II): Las series grabadas, Burgos, Grupo Editorial Fonte / Monte Carmelo, 2017.

MORENO CUADRO, F., Iconografía de Santa Teresa (III): De las visiones a la vida cotidiana, Burgos, Grupo Editorial Fonte / Monte Carmelo, 2018.

MORENO CUADRO, F., Iconografía de Santa Teresa (IV): Iconografía de los reformadores descalzos y la estampa alegórica, Burgos, Grupo Editorial Fonte / Monte Carmelo, 2019.

MORENO CUADRO, F., San Juan de la Cruz y el grabado carmelitano del Teresianum de Roma, Madrid, Ministerio de Cultura, Subdirección General de Cooperación Internacional, 1991. 
MORENO CUADRO, F., «La Inmaculada carmelitana. Concreciones del tipo iconográfico en Europa y Nueva España», Goya: Revista de Arte, nº 370, 2020, pp. 30-47.

PALACIOS BAÑUELOS, L. y MORENO CUADRO, F., San Juan de la Cruz en el grabado, Bilbao, Bilbao Bizkaia Kutxa, 1991.

SERMONES PREDICADOS en la Beatificación de la B. M. Teresa de Iesvs Virgen, Fvndadora de la Reforma de los Descalzos de Nuestra Señora del Carmen, Madrid, Viuda de Alonso Martín, 1615.

TERESA DE JESÚS, Los libros de la B. Madre Teresa de Iesus, fundadora de la Reformacion de los Descalços y Descalças de Nuestra señora del Carmen, Zaragoza, Pedro Cabarte, 1615.

TERESA DE JESÚS, Obras de la Gloriosa madre Santa Teresa de Jesús Fundadora de la Reforma de la Orden de Nuestra Señora del Carmen, de la Primitiva Observancia, Madrid, Joseph de Orga, 1752 (2 vols.).

Fernando Moreno Cuadro

Universidad de Córdoba

Catedrático de Historia del Arte http://orcid.org/0000-0001-8933-0687

it1mocuf@uco.es 

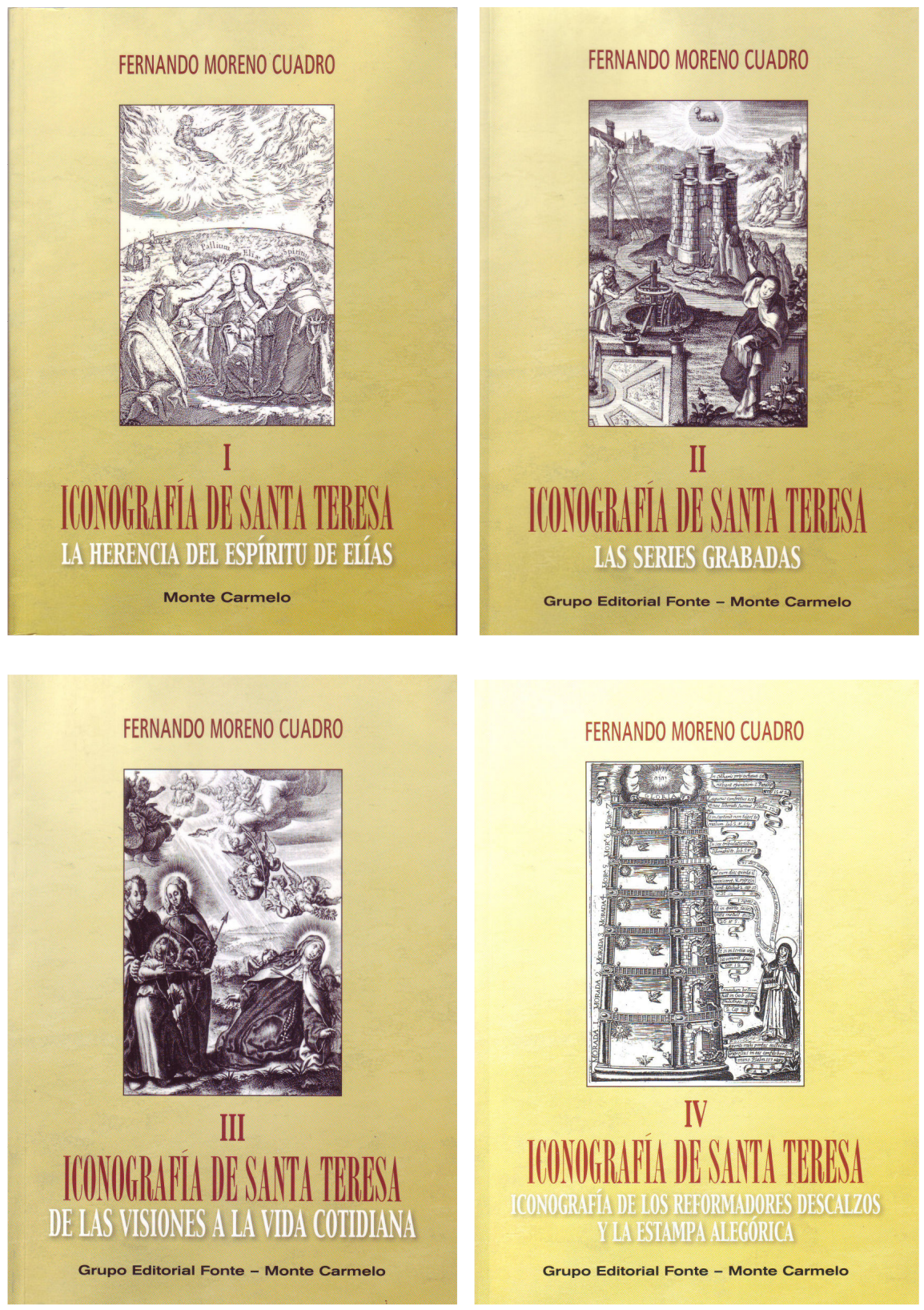

FERNANDO MORENO CUADRO

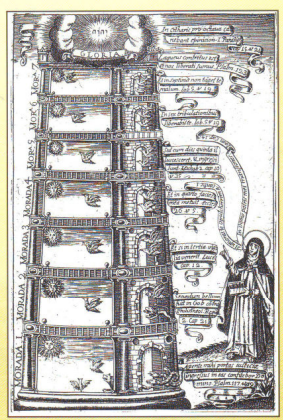

IV

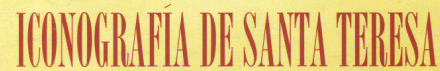

COONOGRAFA DE LOS RERORMADORES DESCAIZZOS Y LA BSTAVPA AIREORRCA

Grupo Editorial Fonte - Monte Carmelo 